\title{
Leptospirosis as a Cause of Acute Respiratory Failure: Clinical Features and Outcome in 35 Critical Care Patients
}

\author{
Silvia R R Vieira and Janete S Brauner
}

Intensive Care Unit, Clinical Hospital of Porto Alegre and N.S. Conceição Hospital, Porto Alegre, RS, Brazil

\begin{abstract}
Leptospirosis may have important complications, such as acute respiratory failure (ARF) associated or not with other organic dysfunction, with a high mortality rate. We report the characteristics and evolution of severe leptospirosis associated with ARF. During 10 years, 35 consecutive adult patients admitted in two general Intensive Care Units with severe leptospirosis and ARF, were followed up. Clinical characteristics, associated organic dysfunction and mortality were analyzed. Survivors were compared with non-survivors. The most frequent clinical manifestations were dyspnea, fever, myalgia, jaundice, hemoptysis and coughing. All patients presented ARF, needing mechanical ventilation, as well as other organic dysfunctions. The mortality rate was $51 \%$. Non-survivors were older and had a higher incidence of organic dysfunction, mainly renal, cardiovascular and neurological failures, as well as a higher level of acidosis. In conclusion, leptospirosis should be considered as a cause of severe ARF and other associated organic dysfunctions.
\end{abstract}

Key Words: Leptospirosis, acute respiratory failure.

Leptospirosis, a zoonosis caused by Leptospiras, is generally found in tropical and rural regions, but cases have been reported in temperate climates and developed countries [1-4]. Rio Grande do Sul, in southern Brazil, is a temperate climate region, with a low incidence of leptospirosis, but at least 30 cases/year have been reported [5]. In Porto Alegre, Rio Grande do Sul, 37 cases were confirmed in 2000 [6]. It is, in general, a self-limiting disease. However, many descriptions of severe cases, with important complications and a high mortality rate, have been reported $[1,5,6]$. Severe forms of the disease are associated with a case-fatality rate of 5 to more than $40 \%$ [7].

The early phase of the disease is generally characterized by fever, chills, headache and severe myalgia [1]. In 5 to $15 \%$ of clinical infections, Received on 20 November 2001; revised 31 March 2002.

Address for correspondence: Dr. Silvia Regina Rios Vieira. Rua São Luis, 1127, 501, Porto Alegre, RS, Brazil, Zip Code: 90620170.E-mail: srvieira@zaz.com.br

The Brazilian Journal of Infectious Diseases 2002;6(3):135-139 (C) 2002 by The Brazilian Journal of Infectious Diseases and Contexto Publishing. All rights reserved.

$1413-8670$ progression to severe multisystemic complications occurs, such as jaundice, renal failure and bleeding disorders [1]. Pulmonary symptoms and signs in patients with leptospirosis have been infrequently described, but in recent years this scenario has changed, with cases of severe hemoptysis and acute respiratory failure (ARF) being described [8-12]. When ARF is present, dyspnea, pulmonary edema, alveolar and interstitial hemorrhages are common clinical-pathological features. Despite considerable knowledge about this disease, questions on its clinical presentation and evolution still need to be addressed [7]. We report our experience with 35 patients presenting severe leptospirosis associated with ARF, including clinical features, morbidity and mortality, in order to better understand the manifestations and outcome of this disease.

\section{Materials and Methods}

All patients admitted with severe leptospirosis associated with ARF, between January 1990 and December 2000, were followed up in an observational 
prospective cohort study. The study was carried out in two general intensive care units (ICU) of two general hospitals (Hospital Nossa Senhora da Conceição and Hospital de Clínicas de Porto Alegre), both located in Porto Alegre, Rio Grande do Sul. Data was prospectively collected during ICU hospitalization. This research was approved by the ethic committees of both hospitals.

The diagnosis of leptospirosis was confirmed in all patients by a blood macroagglutination test. They were analyzed for APACHE II score [13], clinical and laboratory characteristics, associated organic dysfunction, treatment received and mortality rate during ICU stay. ARF included acute lung injury (ALI) and acute respiratory distress syndrome (ARDS), defined as reduced $\mathrm{PaO}_{2} / \mathrm{FIO}_{2}$ ratio, bilateral lung infiltratation and absence of heart failure according to the consensus conference on ARDS [14]. Other organic dysfunctions (hepatic, renal, cardiovascular, hematologic and neurologic) were evaluated according to Fry's classification [15].

The characteristics assessed were: age, gender, symptomatic period before ICU admission, length of stay in ICU, clinical features (dyspnea, fever, myalgia, jaundice, hemoptysis, cough, oliguria and mental confusion) laboratory features (serum bilirubin, creatinine and bicarbonate levels, hematocrit, leucocytes and platelet values, prothrombin time), $\mathrm{PaO}_{2}$ and $\mathrm{FIO}_{2}$ levels, presence of bilateral infiltrates in chest radiograms, capillary wedge pressure measured by a Swan-Ganz catheter, respiratory system compliance calculated as tidal volume divided by inspiratory pressure minus intrinsic positive end-expiratory pressure (PEEP).

Survivors at the time of ICU discharge were compared with non-survivors, taking into account the clinical and laboratory features as well as organic dysfunction.

The continuous variables were compared by an unpaired $t$ test and the categorical variables by the Chisquared test. The criterium for significance was $p<0.05$.

\section{Results}

Thirty-five adult patients, from Porto Alegre or surrounding areas, with severe leptospirosis and ARF (mean age $40+16$ years, 29 men and 6 women) were studied. The mean APACHE value was $20.1 \pm 4.2$. The mean $\mathrm{PaO}_{2} / \mathrm{FIO}_{2}$ ratio was $171 \pm 73$. All patients had diffuse bilateral pulmonary infiltrates. The capillary wedge pressure was normal $(12 \pm 5 \mathrm{~mm} \mathrm{Hg})$ and the respiratory compliance was reduced $(31 \pm 13 \mathrm{~mL} /$ $\left.\mathrm{cmH}_{2} \mathrm{O}\right)$ in all the patients.

The mortality rate was $51 \%(\mathrm{n}=18)$. Non-survivors were significantly older than survivors $(47+15$ versus $32+12$ years, $\mathrm{p}<0.05)$. The APACHE values $(18.6$ \pm 3.7 versus $21.2 \pm 4.4$ ) as well as the $\mathrm{PaO}_{2} / \mathrm{FIO}_{2}$ ratio (188 \pm 64 versus $156 \pm 79)$ were not significantly different, comparing survivors and non-survivors, respectively.

The most frequent clinical and laboratory manifestations are shown in table 1. Survivors had a significantly lower incidence of mental confusion and a lower level of acidosis than non-survivors.

All patients needed mechanical ventilation with PEEP and had some other associated organic dysfunctions, including hepatic, renal, cardiovascular, hematological and neurological dysfunctions (Table 2). Organic dysfunction, mainly renal, cardiovascular and neurological failures occurred significantly more often in non-survivors $(\mathrm{p}<0.05)$.

The symptomatic period, from the initial symptoms till admission into the ICU and the beginning of treatment, was $7.3 \pm 4.5$ days $(7.7 \pm 4.5$ for survivors and $6.9 \pm 4.7$ for non-survivors, $p>0.05$ ). The length of stay in ICU was $12 \pm 10$ days ( $16 \pm 9$ for survivors and $9 \pm 10$ for non-survivors, $\mathrm{p}<0.05)$.

All patients received a similar treatment, which included: antibiotics (Penicillin for all of them and other antibiotics according to bacteriological studies in order to treat complicating infections); mechanical ventilation with PEEP in all of them; fluid replacement as needed to maintain normal pressures; vasoactive drugs in patients with cardiovascular dysfunction (63\%), hemofiltration $(40 \%)$ or peritoneal dialysis $(9 \%)$ as needed for severe renal failure and nutritional support with enteral feeding. There was no difference in the use of dialytic therapy between survivors and nonsurvivors. Vasoactive drugs were used more frequently in non-survivors (Table 2). 
Table 1. Clinical and laboratory findings in patients with leptospirosis and acute respiratory failure

\begin{tabular}{|c|c|c|c|c|}
\hline & $\begin{array}{c}\text { Total } \\
(n=35)\end{array}$ & $\begin{array}{l}\text { Survivors } \\
\quad(n=17)\end{array}$ & $\begin{array}{l}\text { Non-survivors } \\
(\mathbf{n}=\mathbf{1 8})\end{array}$ & p value \\
\hline Dyspnea (n, \%) & $33(94 \%)$ & $16(46 \%)$ & $17(49 \%)$ & NS \\
\hline Fever $(n, \%)$ & $32(91 \%)$ & $17(49 \%)$ & $15(43 \%)$ & NS \\
\hline Myalgia (n, \%) & $30(86 \%)$ & $14(40 \%)$ & $16(46 \%)$ & NS \\
\hline Jaundice (n, \%) & $29(83 \%)$ & $13(37 \%)$ & $16(46 \%)$ & NS \\
\hline Hemoptysis (n, \%) & $26(74 \%)$ & $11(31 \%)$ & $15(43 \%)$ & NS \\
\hline $\operatorname{Cough}(n, \%)$ & $26(74 \%)$ & $12(34 \%)$ & $14(40 \%)$ & NS \\
\hline Oliguria $(\mathrm{n}, \%)$ & $24(69 \%)$ & $11(31 \%)$ & $13(37 \%)$ & NS \\
\hline Mental confusion ( $\mathrm{n}, \%)$ & $11(31 \%)$ & $2(1 \%)$ & $9(26 \%)$ & $\mathrm{p}<0.05$ \\
\hline Creatinine level (mg/dL) (mean+SD) & $4.4+2.6$ & $4.5+2.9$ & $4.3+2.3$ & NS \\
\hline Total bilirubin level (mg/dL) (mean + SD) & $17.1+15.7$ & $17.9+19.7$ & $16.3+10.7$ & NS \\
\hline Bicarbonate level $($ meq $/ \mathrm{L})($ mean $+\mathrm{SD})$ & $15.1+6.7$ & $18.3+4.3$ & $11.3+7.1$ & $\mathrm{p}<0.05$ \\
\hline Hematocrit $(\%)($ mean + SD $)$ & $24.2+6.6$ & $23.2+6.0$ & $25.1+7.2$ & NS \\
\hline Leukocytes $\left(10^{3} / \mu \mathrm{L}\right)($ mean $+\mathrm{SD})$ & $19.0+11.4$ & $19.0+12.0$ & $19.0+11.1$ & NS \\
\hline Platelets $\left(10^{3} / \mu \mathrm{L}\right)($ mean $+\mathrm{SD})$ & $97.8+23.2$ & $104.6+16.1$ & $90.9+14.0$ & NS \\
\hline Prothrombin time (seconds) $($ mean + SD) & $56.8+23.2$ & $59.2+23.9$ & $54.5+23.0$ & NS \\
\hline
\end{tabular}

$\mathrm{p}$ value $=$ comparison between survivors and non-survivors ( $\mathrm{t}$ test for continuous variables or $\chi^{2}$ for categorical variables); $\%=\%$ regarding the total number of patients.

Table 2. Presence of other organic dysfunctions in patients with leptospirosis and acute respiratory failure

\begin{tabular}{lcccc}
\hline & $\begin{array}{c}\text { Total } \\
(\mathrm{n}=35)\end{array}$ & $\begin{array}{c}\text { Survivors } \\
(\mathrm{n}=17)\end{array}$ & $\begin{array}{c}\text { Non-survivors } \\
(\mathrm{n}=18)\end{array}$ & p value \\
\hline Organic dysfunction (n, mean + SD) & $4.1+1.7$ & $3.5+1.6$ & $4.7+1.6$ & $\mathrm{p}<0.05$ \\
Hepatic (n, \%) & $27(77 \%)$ & $13(37 \%)$ & $14(40 \%)$ & $\mathrm{NS}$ \\
Renal (n, \%) & $26(74 \%)$ & $10(29 \%)$ & $16(46 \%)$ & $\mathrm{p}<0.05$ \\
- Hemofiltration (n, \%) & $14(40 \%)$ & $5(14 \%)$ & $9(26 \%)$ & $\mathrm{NS}$ \\
- Peritoneal dialysis (n, \%) & $3(9 \%)$ & $2(6 \%)$ & $1(3 \%)$ & $\mathrm{NS}$ \\
Cardiovascular (n, \%) & $22(63 \%)$ & $7(20 \%)$ & $15(43 \%)$ & $\mathrm{p}<0.05$ \\
-Use of vasoactive drugs (n, \%) & $22(63 \%)$ & $7(20 \%)$ & $15(43 \%)$ & $\mathrm{p}<0.05$ \\
Hematological (n, \%) & $21(60 \%)$ & $10(29 \%)$ & $11(31 \%)$ & $\mathrm{NS}$ \\
Neurological (n, \%) & $11(31 \%)$ & $2(1 \%)$ & $9(26 \%)$ & $\mathrm{p}<0.05$ \\
\hline
\end{tabular}

$\mathrm{p}$ value = comparison between survivors and non-survivors ( $\mathrm{T}$ test for continuous variables or $\mathrm{c}^{2}$ for categorical variables); $\%=\%$ regarding the total number of patients. 


\section{Discussion}

We studied cases of severe leptospirosis that occurred in a country endemic for this disease, but in a a temperate climate region. They were associated with ARF as well as with other organic dysfunctions (hepatic, renal, cardiovascular, hematological or neurological). Mortality was very high, even with adequate treatment.

Leptospirosis is now being considered an emerging infectious disease that is spreading from its traditional rural setting to urban centers [7] with cases being described even in developed and temperate climate countries [2-4]. At the same time, the number of reports of severe leptospirosis associated with hemorrhagic pneumonitis (pulmonary hemorrhage and acute respiratory distress) with a high fatality rate $[1,8,11]$ is increasing in recent years. Our cases, in agreement with this new information from the literature, were found in a temperate climate urban area and involved a severe form of the disease, with ARF, other associated organic dysfunctions and a very high mortality rate.

The most frequent clinical and laboratory manifestations observed in our study (dyspnea, fever, myalgia, jaundice, hemoptysis, cough, elevated serum bilirubin and creatinine levels, anemia, leucocytosis, thrombocytopenia, elevated prothrombin time and acidosis) were similar to those described by other authors [7]. All patients had bilateral pulmonary infiltratation because only those with severe ARF were studied. Recent reports have described a $25.2 \%$ frequency of pulmonary radiograph alterations in patients hospitalized with leptospirosis [16].

In spite of adequate treatment, mortality, in our group of patients, was very high (51\%), higher then in some previous descriptions [7], but similar to others [11]. The cause of our high mortality rate was the fact that only patients admitted to ICUs, with a very severe form of the disease, were included. Comparing non-survivors with survivors, some differences were apparent. Non-survivors were older and had more organic dysfunction, characterizing a group with more severe disease. These results are in agreement with most published reports $[7,9,11]$. Cardiovascular and renal dysfunctions occurred principally in non-survivors, as in previous reports [11]. Neurological dysfunction was also more frequent in the group of non-survivors, which was reported by some authors, but not confirmed by others [7]. In addition, the APACHE value was slightly higher and the $\mathrm{PaO}_{2} / \mathrm{FIO}_{2}$ ratio was slightly lower in non-survivors, though these differences were not significant. It is also important to remember that non-survivors had more intense acidosis, a feature that has not been emphasized in the literature.

Treatment and its delay after the beginning of symptoms did not interfere in mortality. Treatment was similar in all patients, the only difference being the use of vasoactive drugs, more frequent in nonsurvivors, because of their higher cardiovascular instability. The delay between initial symptoms and the initiation of therapy also did not differ between survivors and non-survivors.

A limitation of our data is the small number of patients. Leptospirosis is not very common in our city and only severe cases with ARF were admitted in our ICUs. Because of that, some differences between survivors and non-survivors could have been underestimated. In addition, patients with less severe disease were not admitted to the ICUs and so we have no further information on them.

In conclusion, leptospirosis has to be considered as a cause of severe ARF and other associated organic dysfunctions, having in these cases a very high mortality rate. This is most important in endemic areas but should also be taken into account in other regions.

\section{References}

1. Farr R.W. Leptospirosis. Clin Infect Dis 1995;21:1-6.

2. Hogan M.C., Pate G., McConkey S.J., et al. Leptospirosis in the Republic of Ireland: 1985-1996. Commun Dis Rep CDR Rev 1997; 7:R185-9. 
3. Ciceroni L., Stepan E., Pinto A., et al. Epidemiological trend of human leptospirosis in Italy between 1994 and 1996. Eur J Epidemiol 2000; 16:79-86.

4. Smythe L., Dohnt M., Symonds M., et al. Review of leptospirosis notificatios in Queensland and Australia: January 1998-June 1999. Commun Dis Intell 2000;24:153-7.

5. SSMA. Casos, óbitos e letalidade de leptospirose humana no Rio Grande do Sul no período de 1992-97. Relatório anual da SSMA 1997.

6. Acosta L.M.W. A vigilância epidemiológica da leptospirose em Porto Alegre. Boletim Epidemiológico - Seceretaria Municipal de Saúde de Porto Alegre 2000;3:2-3.

7. Ko A.I., Reis M.G., Dourado C.M.R., et al. Urban epidemic of severe leptospirosis in Brazil. Lancet 1999;354:820-5.

8. Gonçalves A.J.R., Carvalho J.E.M., Silva J.B.G., et al. Hemoptysis and the adult respiratory distress syndrome as the causes of death in leptospirosis: changes in the clinical and anatomicopathological patterns [in Portuguese]. Rev Soc Bras Med Trop 1992;25:261-70.

9. Courtin JP, DiFrancia M, DuCouedic I, Poubeau P, Mahe C, Bapteste J, Arvin-Berod C. Les manifestations respiratoires de la leptospirose. Etude retrospective de 91 cas (1978-1994). Rev Pneumol Clin 1998;54:382-92.

10. Trevejo R.T., Rigau-Pérez J.G., Ashford D.A., et al. Epidemic leptospirosis associated with pulmonary hemorrhage-Nicaragua, 1995. J Infect Dis 1998; 178:1457-63.

11. Marotto P.C., Nascimento C.M., ElufNeto J., et al. Acute lung injury in leptospirosis: clinical and laboratory features, outcome, and factors associated with mortality. Clin Infect Dis 1999;29:1561-3.

12. Yersin C., Bovet P., Merien F., et al. Pulmonary haemorrhage as a predominant cause of death in leptospirosis in Seychelles. Trans Soc Trop Med Hyg 2000;94:71-6.

13. Knaus W.A., Draper E.A., Wagner D.P., Zimmerman J.E. APACHE II: a severity of disease classification system. Crit Care Med 1985; 13:818-29.

14. Bernard G.R., Artigas A., Brigham K.L., et al. The American-European Consensus Conference on ARDS. Definitions, mechanisms, relevant outcomes, and clinical trial coordination. Am J Respir Crit Care Med 1994;149:818-24.

15. Fry D.E. Multiple system organ failure. Surg Clin North Am 1988;1988:107.

16. Matos E.D., Costa E., Sacramento E., et al. Chest radiograph abnormalities in patients hospitalized with leptospirosis in the city of Salvador, Bahia, Brazil. Braz $\mathrm{J}$ Infect Dis 2001;5:73-7. 